\title{
The Effects of Using Scoring Rubrics and Self-Regulation Strategies on the EFL Intermediate Students' Reading Gains
}

\author{
Hasneh, Gorjipour ${ }^{1,}$ \& Maedeh, Hoseinpoor ${ }^{2}$ \\ ${ }^{1}$ Faculty of Persian Literature and Foreign Languages, Allameh Tabataba'i University, Tehran, Iran \\ *Correspondence: Faculty of Persian Literature and Foreign Languages, Allameh Tabataba'i University, Tehran, Iran. \\ E-mail: H87.Gorjipour@gmail.com
}

Received: September 9, 2018

Accepted: October 31, 2018 Online Published: December 11, 2018

doi:10.5430/ijelt.v6n1p20

URL: https://doi.org/10.5430/ijelt.v6n1p20

\begin{abstract}
Rubrics are considered beneficial for both teaching and learning, especially when they are practiced as formative assessment (Panadero \& Jonsson, 2013). By applying self-regulation strategies together with reading based rubric, this study mainly intended to examine the effects of rubrics and self-regulation strategies on the Iranian learners' reading comprehension gains across gender. The participants of the study were 60 male and female EFL students selected based on their PET scores. Subsequently, a pretest of reading comprehension was administered to the groups of experimental and control as well as male and female groups to determine their proficiency level. Then, the experimental group underwent training on how to use reading rubric and self-regulation strategies. At the end of the course, the reading comprehension post-test was re-administered. The findings suggested that there was a statistically significant difference between rubric-oriented classes in conjunction with learners' use of self-regulation strategies and rubric-free classes in terms of the students' reading comprehension gains. Furthermore, the results showed that the male learners outperformed their female counterparts in utilizing self-regulation strategies and rubrics in reading comprehension. Moreover findings suggested some theoretical and pedagogical implications for the language learners, teachers, and syllabus designers.
\end{abstract}

Keywords: Rubric, self-regulation strategies, reading comprehension gains, self-regulation, gender.

\section{Introduction}

It is frequently said that the ultimate purpose of language learning is to enable learners communicate well. To achieve this goal, learners should determine their own learning strategies as well as evaluate their learning results. Put it other way, they need to self-regulate their own learning, taking on more responsibility on their path to language learning. Zimmerman (2000) characterized self-regulation as the extent to which learners are engaged in their learning process and in achieving their goals. Moreover, in the process of reading comprehension, the learners can employ certain strategies to enhance their performance. One of these strategies is self-regulation. Pintrich (2000, p. 154), gave the following definition of self-regulation: "an active, constructive process whereby learners set goals for their learning and then attempt to monitor, regulate, and control their cognition, motivation, and behavior, guided and constrained by their goals and contextual features of the environment".

Another concern of this study was rubric. It is "a scoring tool that lays out the specific expectations for an assignment" (Stevens \& Levi, 2005, p. 3). They further noted that assessment could be more effective and efficient through employing rubrics since acceptable or unacceptable levels of performance for each part of given task are clearly specified. Along the same lines, Reddy (2007) focuses the facilitative role of rubrics in reporting the achievement of students and emphasizes the fact that rubrics provide the foundation for justifying the decisions teacher make in the evaluation process. He further contends that rubrics can also be utilized to foster learning and the development of sophisticated thinking skills. In the same context, Andrade (2000) asserts that when rubrics are used appropriately, they can serve both the purpose of instruction as well as assessment.

The present study deals with the effectiveness of applying a reading based rubric together with self-regulation strategies on the EFL learners' reading gains across gender. To this end, this study examines the differences between the uses of rubric in conjunction to self-regulation strategies, compared to rubric free classes in terms of learners' 
reading comprehension gains. Training of self-regulation strategies was based on Zimmerman and Moylan's (2009) cyclical model of self-regulation. With rubrics learners have access to a well-defined criterion based on which they can assess their reading comprehension performance (Perlman, 2003). Rubrics are also teaching tools that support students' learning (Panadero \& Jonsson, 2013)

The prime problem addressed in this study is that assessment is not in keeping with current knowledge about human cognition and learning. Hence, assessing learners' performance, and achievement, should be based on current scientific understanding of how learners represent knowledge and develop competence. Moreover, reading is a core skill in our life and it is important for the mind and the success of pupils' academic career as people who cannot read well, lose a lot of important things in their life. One of the ways in which the process of reading comprehension can take place more effectively is through assessing and regulating one's own performance using rubrics and self-regulation strategies.

\section{Theoretical and Empirical Background}

Rubric is considered as a type of a criteria-specific performance scale which consists of set of scoring criteria used to distinguish the achievement level of the learners' performance on given tasks. As a matter of fact, a rubric breaks down a task into its components and gives detailed accounts and description of the performance levels of each component (Andrade \& Reddy, 2010). Panadero, Romero and Strijbos, (2013, p. 133) argues that: "assessment criteria are the standards against which the execution and the final outcome of a task are evaluated". They further contend that, students, especially those at the lower level of their education, in order to assess themselves appropriately need to clearly understand and digest these criteria.

Although Panadero, Romero and Strijbos (2013) argue that rubrics are used widely at different levels of education, the research on the formative uses of rubrics has not been conclusive regarding whether or not the use of rubrics actually enhances students' performance. The use of rubrics also allows us to move from a deficit model of assessment to a more positive and useful formative model (Lazear, 1998). But recently, the use of rubrics for formative purposes is being focused more. The use of rubric formatively can help promote the students' learning and help teachers in a better instruction (Panadero \&Jonsson, 2013).

As it has been mentioned the unique features of rubrics do not only make them suitable instruments for enhancing the psychometric properties of performance assessments, but also for supporting in the process of formative assessment, and along the same line aid the learners in their learning development (Panadero \& Jonsson, 2013). Equally important there are some researches that stated that using rubrics in the class would improve the learners' improvement on learning (Andrade \& Du, 2005; Panadero \& Alonso-Tapia \& Huertas 2012; Panadero, Romero \& Strijbos, 2013).On the other hand, Stevens and Levi (2005) believe that rubrics encourage students to think critically about their own learning and help in self-improvement.

From the background provided in this literature review, a number of conclusions can be reached. It has been indicated that rubrics appear to yield positive outcomes. For example, Panadero and Alonso-Tapia and Huertas (2012) argue that the evidence about their effectiveness for improving self-regulation is solid. In another word, rubrics serve as self-assessment tools characterized by the following features: a set of criteria that is used to assess the important goals of the task, a scale for grading the different levels of achievement and a description for each qualitative level.

Furthermore, some studies have investigated the effect of rubrics on self-regulation (Andrade \& Du et al., 2009; Jonsson \& Svingby, 2007). The findings showed that the application of rubrics in some circumstance made contributions to enhancement of self-regulation. To evaluate the effects of using rubrics on improving learners' self-regulation, Panadero, Romero and Strijbos, (2013) compared the effect of using rubrics and scripts on improving learners' self-regulation. To evaluate students' self-regulation they used two kinds of questionnaires following Samuelstuen and Braten's idea, (2007), General self-regulation questionnaire: Emotion and Motivation Self-regulation Questionnaire (EMSR-Q) and Specific self-regulation questionnaire (SSR). After a ten week course students who used script showed higher self-regulation and using rubrics lessens avoidance self-regulation (negative self-regulatory actions detrimental to learning).

Despite the contribution of the abovementioned studies, there are still very few studies examining the potential contributions rubrics and self-regulation might make to the improvement of reading comprehension in Iran. A more detailed study can be provided by using reading-based analytic rubric and applying self-regulation strategies to help learners' reading gains. Thus, this study sought to address this effect. Accordingly, in order to determine the impact of rubric and self-regulation strategies on the students' reading gains, the following questions were formulated: 
RQ1. Is there any statistically significant difference between rubric-oriented classes in conjunction with learners' use of self-regulation strategies and rubric-free classes in terms of the students' reading comprehension gains?

RQ2. Is there any statistically significant difference between the effects of rubric use on the students' reading gains in Iranian EFL male and female learners' performance?

\section{Methodology}

\subsection{Participants and Setting}

The participants of the study were 60 EFL students, randomly assigned and divided into two groups of experimental and a control based on Preliminary English Test (PET). The participants were male and female learners ranging from 17 to 25, learning English in a language institute in Tehran, Iran.

\section{Materials and instruments}

\subsection{Reading-Based Analytic Rubric}

The reading Rubric developed by the researcher based on Bloom's taxonomy (Munzenmair and Rubin, 2013) was used. After the rubric was presented to the students, based on the feedback model, the rubric was discussed with the whole class. Each section, the language learners were asked to judge themselves based on the presented rubric. It should be noted that the students were given assistance whenever they had a problem as to how to score themselves using the rubric.

\subsection{Preliminary English Test (PET)}

The sample of Preliminary English Test was extracted from Preliminary English Test 5 of Cambridge ESOL Examinations published by Cambridge University Press (Quintana, 2011), and administered to determine the learners' overall proficiency prior to the study.

\subsection{Reading Comprehension Pretest and Posttest}

To ensure the homogeneity of the participants' reading comprehension, a reading comprehension pretest including four different texts designed by the teacher was utilized. It consisted of 35 questions. The allotted time was $60 \mathrm{~min}$. The posttest was the same as the pretest except the sequence of the items was changed to avoid practice effect on the part of the participants.

\section{Procedure}

First, a PET proficiency test was administered to 90 Iranian EFL students. The students, whose scores were within the range of one standard deviation above and one below the mean were selected as the main participants of the study. Based on their scores, 60 learners were selected and randomly assigned to two groups of the experimental and control group $(\mathrm{N}=30)$. It should be noted here that the selected participants were then divided into two equal groups in terms of gender (male $=20$, female $=20$ ). Thus, there were four groups of the participants as an experimental, a control, a female and a male groups. Then, a pretest of reading comprehension was administered to the groups to determine their reading proficiency level at the outset of the study.

The experimental group underwent training on how to use rubrics and self-regulation strategies. At the beginning of treatment, instruction was devoted to the discussion on rubric and editing the designed rubric based on the feedback model. Based on this model "the rubric is completely designed by the teacher but before the teacher finalizes the rubric, the students are presented with a completed rubric and given the chance to discuss the rubric to revise it by making edits, offering ideas, and asking questions" (Stevens \& Levi, 2005, p. 56). From the second session onward, 20 minutes of the class time were devoted to the reading comprehension. While working on the reading skill, the teacher explained the self-regulation strategies and helped the students follow the strategies and steps. To this end, the students used the rubrics as one of the necessary steps along with self-regulation strategies. The training of self-regulation strategies was based on Zimmerman and Moylan's (2009) cyclical model of self-regulation. This model consists of three phases: Forethought, Performance, and Self-reflection. Each phase includes the following sub-processes: Forethought phase (Task analysis, goal setting, strategic planning, self-motivation beliefs, self-efficacy, Outcome expectations, Intrinsic interest / value Goal orientation), performance 
phase (Self-control, Self-instruction, Imagery, attention focusing, task strategies, self-observation metacognitive monitoring), and self-reflection phase (Self-judgment, Self-evaluation, Causal attribution, Self-reaction, Self-satisfaction, Adaptive / defensive). However, in control group, the learners participated in reading activities with no special instruction on reading rubric and self-regulation strategies. At the end of the course, the posttest of reading comprehension was administered to all groups to find out which group had gained better performance in terms of reading comprehension.

\section{Data Analysis}

The results of the tests, administered to four groups were analyzed by (SPSS. 22). In order to answer the first and second research questions, it was required to compare the reading comprehension gain scores of the students in experimental and control groups as well as male and female groups; therefore, ANCOVA and independent samples t-test were run, respectively.

\section{Results}

Before conducting ANCOVA, it was essential to ensure of normality, which was found met based on the normality tests results in Table $1(\mathrm{p}<.05)$.

Table 1. Tests of Normality

\begin{tabular}{llcccccc}
\hline \multirow{2}{*}{ Control.Exp } & \multicolumn{3}{c}{ Kolmogorov-Smirnov $^{\mathbf{a}}$} & \multicolumn{3}{c}{ Shapiro-Wilk } \\
\cline { 2 - 7 } & Statistic & df & Sig. & Statistic & df & Sig. \\
\hline \multirow{2}{*}{ Pretest } & Control & .12 & 30 & $.20^{*}$ & .95 & 30 & .18 \\
& Experimental & .10 & 30 & $.20^{*}$ & .95 & 30 & .25 \\
\multirow{2}{*}{ Posttest } & Control & .19 & 30 & .00 & .91 & 30 & .01 \\
& Experimental & .15 & 30 & .07 & .95 & 30 & .24 \\
\hline
\end{tabular}

*. This is a lower bound of the true significance.

a. Lilliefors Significance Correction

The next assumption is to do with the homogeneity of variances, which was found met according to the results of Levene's test in Table $2(\mathrm{p}>.05)$.

Table 2. Levene's Test of Equality of Error Variances ${ }^{\mathrm{a}}$

\begin{tabular}{cccc}
\hline F & df1 & df2 & Sig. \\
\hline 3.73 & 1 & 58 & .05 \\
\hline
\end{tabular}

Tests the null hypothesis that the error variance of the dependent variable is equal across groups. a. Design: Intercept + Pretest + Control.Exp

The first row indicates that the assumption of homogeneity of regression slopes is met; Interaction $\mathrm{F}(1,57)=.72$, $\mathrm{p}>.05$.

Table 3. Tests of Between-Subjects Effects

Dependent Variable: Posttest

\begin{tabular}{lcccc}
\hline Source & df & F & Sig. & Partial Eta Squared \\
\hline Control.Exp * Pretest & 1 & .72 & .39 & .01 \\
Pretest (covariate) & 1 & 134.56 & .00 & .70 \\
Control.Exp & 1 & 50.43 & .00 & .46 \\
Error & 57 & & & \\
Total & 60 & & & \\
Corrected Total & 59 & & & \\
a. R Squared $=.732$ (Adjusted R Squared $=.723$ ) & & & \\
\hline
\end{tabular}


The second row shows that the groups were indeed different on the pretest; pretest effect $F(1,57)=134.56, p<.05$, and finally the third row demonstrates that the groups are significantly different on the posttest; Group $F(1,57)=$ $50.43, \mathrm{p}<.05$, eta squared $=.46$ medium to large effect size. The results of descriptive statistics are also presented in Table 4.

Table 4. Adjusted Means after Controlling the Covariate

\begin{tabular}{|c|c|c|c|c|}
\hline \multicolumn{5}{|c|}{ Dependent Variable: Posttest } \\
\hline \multirow[t]{2}{*}{ Control. Exp } & \multirow[t]{2}{*}{ Mean } & \multirow[t]{2}{*}{ Std. Error } & \multicolumn{2}{|c|}{ 95\% Confidence Interval } \\
\hline & & & Lower Bound & Upper Bound \\
\hline Control & $15.762^{\mathrm{a}}$ & .338 & 15.084 & 16.439 \\
\hline Experimental & $19.205^{\mathrm{a}}$ & .338 & 18.527 & 19.882 \\
\hline
\end{tabular}

Therefore, it could be stated that there is a statistically significant difference between rubric-oriented classes (experimental) in conjunction with learners' use of self-regulation strategies and rubric-free classes (control) in terms of the students' reading comprehension gains.

In order to answer the second research question, stating whether there was any significant difference between male and female learners concerning the use of rubrics and self-regulation strategies in terms of reading comprehension gains, an independent samples t-test was run to compare the performance of two groups.

Table. 5. Independent Samples T-test Results.

\begin{tabular}{|c|c|c|c|c|c|c|c|c|}
\hline \multirow[t]{2}{*}{ Groups } & \multirow[t]{2}{*}{$\mathrm{N}$} & \multirow[t]{2}{*}{ Mean } & \multirow[t]{2}{*}{$\mathrm{SD}$} & \multicolumn{5}{|c|}{$\begin{array}{l}\text { Levene's Test for t-test for Equality of Means } \\
\text { Equality of Variances }\end{array}$} \\
\hline & & & & $\mathrm{F}$ & Sig. & $\mathrm{t}$ & df. & Sig. (2-tailed) \\
\hline Male & 20 & 63.7 & 1.48 & 14.62 & 0.000 & 3.077 & 39 & 0.011 \\
\hline Female & 20 & 62.3 & & & & & & \\
\hline
\end{tabular}

According to Table 5., the mean of the male group is 63.7, and that of the female group is 62.3 with the level of significance of .000 . Since the level of Sig. was less than 0.05 , and $\mathrm{F}(2,39)=14.62, p<.05)$, thus, it was concluded that there was a significant difference between two groups' performance in the posttest. That is to say, the male group outperformed their counterparts in the female group, thereby answering the second research question.

\section{Discussion}

The current study was set to investigate whether there was any statistically significant difference between rubric-oriented classes in conjunction with learners' use of self-regulation strategies and rubric-free classes in terms of the students' reading comprehension gains. In addition, it explored whether there was any statistically significant difference between the effects of rubric use on the students' reading gains in Iranian EFL male and female learners' performance.

The findings revealed that rubrics and self-regulation strategies had a significantly positive effect on Iranian EFL reading comprehension. Morever, the results indicated that the rubrics and self-regulation strategies had a stronger effect on Iranian EFL male learners compared to Iranian EFL female learners regarding their reading comprehension performance.

The findings in this study are generally consistent with Panadero, Alonso-Tapia and Huertas (2012), who indicated that rubrics have the potentials to influence learning positively. Moreover, the results of the study are in line with the findings of Andrade and Du (2005), who presented a performance rubric to the class to help their students perform better in the class. Furthermore, in a research by Panadero and Jonsson (2013), they reviewed about 21 researches on the formative use of rubrics and concluded that rubrics can lead to a better performance.

However, the findings of this research are to some extent in conflict with Andrade (2001). He examined the effects of writing rubric on the students' writing improvements. The results showed that in the three writings that the students wrote, their average performance in the second writing were better than the control group. Another research findings which are to some extent in contrast with the present research are Sadler's (2009, as stated in Smith and 
Worsfold et al., 2013). He believed that rubrics as a tool for developing students' learning might be restricted by the problems of what the rubric provider writes in the rubric from his/her own perspective, may be inscrutable and inaccessible to the students, and may be so meaningless as an aid to learning.

Overall, regarding the research questions, it can be discussed that these findings are in line with many other studies (Andrade \& Du, 2005; Laurian \& Fitzgerald, 2013; Panadero, Alonso-Tapia, Huertas, 2012; Panadero, Romero \& Strijbos, 2013; Sundeen, 2014), which stated that using rubric in the class would assist the students in improving their learning and performance.

Another study, whose results were consistent with the findings of the present research, is by Laurian and Fitzgerald (2013). In that study, a considerable number of the students expressed their agreement and satisfaction in relation to the possibility of working with rubric as a fair and objective tool of assessment. Furthermore, a study done by Reynolds-Keefer (2010) on the undergraduate students of educational psychology revealed not only their positive attitudes toward rubrics but also their tendency to use rubric when they become teachers.

\section{Conclusions}

In conclusion, it should be mentioned that using rubrics as a learning tool is a new method in EFL classes, and especially in the reading skill instruction. The gained results from this study as well as some other studies revealed that it is one of the beneficial techniques whose advantages suppressed its disadvantages. The reading rubric use in conjunction with self-regulation strategies, unlike the conventional and traditional one way teaching models, enables the students to control their own learning and find their problematic areas and weaknesses while reading different texts. This method can help learners become more active readers and receive feedback from themselves (Andrade \& $\mathrm{Du}, 2005)$. Hence, their reading proficiency would increase and they become better and more self-regulated learners (Panadero \& Jonsson, 2013).

The pedagogical and theoretical implications of the present research can contribute to the body of research on the reading instruction. The results of the present study are to the benefit of the teachers, who are seeking an effective way for teaching reading skill to the students. This study also suggests that there are great advantages in using rubric and self-regulation strategies and improving the reading skill of the students. In general, using reading rubrics can have positive effects on the learners such as identifying the important areas in the reading skill, realizing their own needs, providing a situation for student-centered learning techniques. Furthermore the findings of the present study can help syllabus designers and material developers to take advantage of the rubric and self-regulation strategies and sequence the most appropriate teaching materials.

\section{References}

Andrade, H. G. (2000). Using rubrics to promote thinking and learning. Educational leadership, 57(5), 13-19.

Andrade, H. G. (2001). The effects of instructional rubrics on learning to write. Current issues in education, 4(4), 4-12.

Andrade, H. L., \& Du, Y. (2005). Student perspectives on rubric-referenced assessment. Practical Assessment, Research and Evaluation, 10(3), 1-11.

Andrade, H. L., Wang, X., Du, Y., \& Akawi, R. L. (2009). Rubric-referenced self-assessment and self-efficacy for writing. The Journal of Educational Research, 102(4), 287-302. https://doi.org/10.3200/JOER.102.4.287-302

Andrade, H., \& Valtcheva, A. (2009). Promoting learning and achievement through self-assessment. Theory into Practice, 48(1), 12-19. https://doi.org/10.1080/00405840802577544

Auerbach, C. F., \& Silverstein, L. B. (2003). Qualitative data: An introduction to coding and analysis. New York, NY: New York University press.

Borg, S. (2006). Teacher Cognition and Language Education: Research and Practice. London: Continuum.

Halonen, J. S., Bosack, T., Clay, S., \& McCarthy, M. (2003). A rubric for learning, teaching, and assessing scientific inquiry in psychology. Teaching of Psychology, 30, 196-208. https://doi.org/10.1207/S15328023TOP3003_01

Jonsson, A., \& Svingby, G. (2007). The use of scoring rubrics: Reliability, validity and educational consequences. Educational Research Review, 2(2), 130-144. https://doi.org/10.1016/j.edurev.2007.05.002

Laurian, S., \& Fitzgerald, j. (2013). Effects of using rubrics in a university academic level Romanian literature class. 
Procedia - Social and Behavioral Sciences 76, 431-440. https://doi.org/10.1016/j.sbspro.2013.04.141

Lazear, D. (1998). The rubrics way: Using multiple intelligences to assess understanding. USA: Zephyr Press.

Munzenmaier, C., \& Rubin, N. (2013). Bloom's taxonomy: What's old is new again. Perspectives. The eLearning Guild. Retrieved from http://educationalelearningresources.yolasite.com/resources/guildresearch_blooms2013 (1).pdf.

Panadero, E., \& Alonso-Tapia, J. (2014). How do students self-regulate? Review Zimmerman's cyclical model of self-regulated learning. Anales de Psicologia/Annals of Psychology, 30(2), 450-462.

Panadero, E., \& Jonsson, A. (2013). The use of scoring rubrics for formative assessment purposes revisited: A review. Educational Research Review, 9(0), 129-144. https://doi.org/10.1016/j.edurev.2013.01.002

Panadero, E., Alonso-Tapia, J., \& Huertas, J. A. (2012). Rubrics and self-assessment scripts effects on self-regulation, learning and self-efficacy in secondary education. Learning and Individual Differences, 22(6), 806-813. https://doi.org/10.1016/j.lindif.2012.04.007

Panadero, E., Romero, M., \& Strijbos, J. W. (2013). The impact of a rubric and friendship on construct validity of peer assessment, perceived fairness and comfort, and performance. Studies in Educational Evaluation, 39(4), 195-203. https://doi.org/10.1016/j.stueduc.2013.10.005

Perlman, C.L. (2003). Performance assessment: Designing appropriate performance tasks and scoring rubrics. In Wall, J.E and Walz, G.R (Eds.), Measuring up: Assessment Issues for Teachers, Counselors, and Administrators (pp. 497-506). Greensboro, NC: CAPS1Press

Pintrich, P. R. (2000). Multiple goals, multiple pathways: The role of goal orientation in learning and achievement. Journal of Educational Psychology, 92(3), 544-555. https://doi.org/10.1037/0022-0663.92.3.544

Reddy, Y. M. (2007). Effect of Rubrics on Enhancement of Student Learning. Education Journal, 7(1), 3-17.

Reddy, Y. M., \& Andrade, H. (2010). A review of rubric use in higher education. Assessment and Evaluation in Higher Education, 35(4), 435-448. https://doi.org/10.1080/02602930902862859

Reynolds-Keefer, L. (2010). Rubric-referenced assessment in teacher preparation: An opportunity to learn by using. Practical Assessment, Research and Evaluation, 15(8), 1-9.

Samuelstuen, M. S., \& Bra ten, I. (2007). Examining the validity of self-reports on scales measuring students' strategic processing. British Journal of Educational Psychology, 77(2), 351-378. https://doi.org/10.1348/000709906X106147

Smith, C. D., Worsfold, K., Davies, L., Fisher, R., \& McPhail, R. (2013). Assessment literacy and student learning: the case for explicitly developing students 'assessment literacy'. Assessment and Evaluation in Higher Education, 38(1), 44-60. https://doi.org/10.1080/02602938.2011.598636

Stevens, D. D., \& Levi, A. J. (2005). Introduction to rubrics. Sterling, Virgina: Stylus Publishing, LLC.

Sundeen. T. (2014). Instructional rubrics: Effects of presentation options on writing quality. Assessing Writing, 21, 74-88. https://doi.org/10.1016/j.asw.2014.03.003

Zimmerman, B. J. (2000). Attaining self-regulation: a social cognitive perspective. In M. Boekaerts, P. R. Pintrich, and M. Zeidner (Eds.), Handbook of self-regulation. San Diego: CA: Academic Press. https://doi.org/10.1016/B978-012109890-2/50031-7

Zimmerman, B. J., \& Moylan, A. R. (2009). Self-regulation: Where metacognition and motivation intersect. In D. J. Hacker, J. Dunlosky and A. C. Graesser (Eds.), Handbook of Metacognition in Education (pp. 299-315). New York: Routledge. 